\title{
Thermoelectric Power, Electrical Resistivity and Magnetic Properties of Ni-Sm Nano-particles
}

\author{
Gopal Boda ${ }^{1}$, Nehru Boda ${ }^{2}$, Rapolu Sridhar $^{3}$, A. Panasa Reddy ${ }^{1}$,D. Ravinder ${ }^{2, *}$ (iD \\ Department of chemistry, University College Of Science Osmania University, Hyderabad \\ Department of physics, Osmania University, Hyderabad, 500007, Telangana, India \\ Department of Basic Science and Humanities, Vignan Institute of Technology and Science, Deshmukhi (V), Yadadri- \\ Bhuvanagiri Dist. 508 284, Telangana, India \\ * Correspondence: ravindergupta28@ rediffmail.com; rapolu31@ gmail.com;
}

Scopus Author ID 57190787725

Received: 28.05.2020; Revised: 26.06.2020; Accepted: 28.06.2020; Published: 4.07.2020

\begin{abstract}
Nanocrystalline Samarium doped Nickel ferrites having compositional formula $\mathrm{NiSm}_{\mathrm{X}} \mathrm{Fe}_{2}$ $\mathrm{xO}_{4}(0.00 \leq \mathrm{X} \geq 0.10)$ were prepared by the citrate-gel auto combustion method and sintered at $500^{\circ} \mathrm{C}$. The structural characteristics such as XRD analysis were shown cubic spinel structure, and the structural parameters like lattice parameter, X-ray density, bulk density, and porosity variations with Sm doping were studied. The surface morphology of prepared samples was observed by Scanning Electron Microscopy (SEM). The magnetic parameters were studied at room temperature with VSM, and the observed results are discussed with composition. The DC electrical properties were studied using a twoprobe method in the temperature range from room temperature to well beyond Curie temperature. Thermoelectric power studies were carried out from room temperature to well beyond transition temperature with a differential method. The Seebeck coefficient variation with temperature was studied, and it shows the prepared samples are classified as n-type semiconductors. The observed results can be explained on the basis of the conduction mechanism.
\end{abstract}

Keywords: Nano ferrites; XRD; Magnetic properties; DC Conductivity; Thermo electric power.

(c) 2020 by the authors. This article is an open-access article distributed under the terms and conditions of the Creative Commons Attribution (CC BY) license (https://creativecommons.org/licenses/by/4.0/).

\section{Introduction}

Nanocrystalline spinel ferrites are important electrical and magnetic materials that have attracted several researchers because these materials are equally applicable in the electronic industry as well as in biomedical applications [1-3]. The electrical and magnetic properties of Nickel nano ferrites include high electrical resistivity, moderate saturation magnetization, and high coercivity. These properties along with good chemical stability and mechanical hardness make it suitable in electronic industries such as magnetic spin filters [4], data storage [5], $\mathrm{read} /$ write heads [6], microwave absorber [7], etc. and in biomedical areas, they are very useful for magnetic resonance imaging (MRI) contrast enhancement [8], bio-magnetic separation [9], tumor treatment by hyperthermia, drug delivery and release [10], magnetic resonance imaging [11], catalysis [12], drug targeting [13], etc.

Nano spinel ferrites show special electric and magnetic properties, which are quite different from the bulk ferrite materials. Thermoelectric power studies and Hall Effect are widely used in the interpretation of the conduction mechanism in semiconductors. The result of the interpretation of Hall Effect reveals more straight forwarding precise results. However, in the case of mobility semiconductors such as ferrites, it is sometimes difficult to measure the 
Hall Effect. In such cases, the study of thermoelectric measurements is the only alternative. The measurement of thermo e.m.f gives vital information about the type of conduction in semiconductors, whether they are n-type or p-type.

In several earlier reports showed that the property of ferrite nanoparticles might be enhanced by doping rare earth metal elements [14-15]. In addition, the effect of rare earth elements such as $\mathrm{Ce}, \mathrm{Tb} \& \mathrm{Dy}$ in the Ni-ferrite spinel structure was clearly reported concerning various electrical and magnetic properties [16-20]. According to the literature survey, it can be extracted that very limited literature is available for $\mathrm{Sm}$ doped Ni nanoferrites. Hence in the present manuscript, we have synthesized $\mathrm{NiSm}_{X} \mathrm{Fe}_{2}-\mathrm{X} \mathrm{O}_{4}(0.00 \leq \mathrm{X} \geq 0.10)$ by the citrate-gel auto combustion method and the structural, magnetic properties, and electrical transport properties investigation is reported.

\section{Materials and Methods}

\subsection{Experimental method.}

The Nickel-Samarium nanoferrites having the chemical formula $\mathrm{NiSm}_{\mathrm{x}} \mathrm{Fe}_{2-\mathrm{x}} \mathrm{O}_{4}$ (Where $\mathrm{x}=0.00,0.010,0.030,0.050,0.070,0.090$, and 0.10 ) were synthesized by citrate gel auto combustion method using the raw materials. Nickel nitrate $\left[\mathrm{Ni}\left(\mathrm{NO}_{3}\right)_{2}\right]$, Samarium nitrate $\left[\mathrm{Sm}\left(\mathrm{NO}_{3}\right)_{3}\right] 6 \mathrm{H}_{2} \mathrm{O}$, Ferric nitrate $\left(\mathrm{Fe}\left(\mathrm{NO}_{3}\right)_{3}{ }_{9} \mathrm{H}_{2} \mathrm{O}\right.$, Citric acid $\left(\mathrm{C}_{6} \mathrm{H}_{8} \mathrm{O}_{7} \mathrm{H}_{2} \mathrm{O}\right)$ and Ammonia Solution $\left(\mathrm{NH}_{3}\right)$. The chemicals are weighed according to the stoichiometric proportion. The calculated quantities of metal nitrates were dissolved in a minimum amount of distilled water to get a clear homogeneous solution. An aqueous solution of Citric acid is used as a fuel because, among all other fuels, citric acid has a better complexing ability. The metal nitrate to citric acid ratio was maintained as 1:3 for all the samples, and a nitrate-citrate solution is obtained to that Ammonia $\left(\mathrm{NH}_{3}\right)$ solution is added drop by drop to maintain $\mathrm{pH} 7$. The solution is mixed and heated by continuous stirring up to $100^{\circ} \mathrm{C}$ for $10-12$ hours, then a viscous gel is formed, and the remaining water in the mixture is evaporated and forming a dry gel. It generates internal combustion and forms a brown colored product, which is the desired sample; the collected ferrite powder is subjected to calcination at $500^{\circ} \mathrm{C}$ for four hours.

\subsection{Structural Characterizations.}

The structural characterization was done by X-Ray Diffractometer Bruker D8 advanced system with a diffracted monochromatic beam with $\mathrm{Cu} k \alpha$ radiation of wavelength $\left(1.5405 \mathrm{~A}^{0}\right)$. The diffraction pattern of Ni-Sm samples recorded between the Braggs angles $10^{\circ}$ to $80^{\circ}$ in the steps of $0.04^{\circ} \mathrm{sec}$. The crystallite size was estimated from the most intense (311) Bragg peak using the Scherer's formula as given in an equation [21].

$$
D_{x r d}=\frac{0.91 \lambda}{\beta \cos \theta}
$$

Where $\lambda$ - X-ray wavelength, $\theta$ - angle of Bragg diffraction

$\beta$ - Full width at half maxima of the peak.

The lattice parameter value is measured from d-spacing value corresponding Miller indices (h k l) with the following equation [22].

Lattice parameter $a=\frac{d_{h k l}}{\sqrt{h^{2}+k^{2}+l^{2}}}$

The X-ray density was calculated by the following formula [23].

The X-ray density $d_{X}=\frac{n M}{a^{3} N} \mathrm{~g} / \mathrm{cm}^{3}$ 
Where $\mathrm{n}$ is the number of molecules in a unit cell of spinel lattice $(\mathrm{n}=8)$,

$\mathrm{M}=$ molecular weight of the sample

$\mathrm{N}$ is the Avogadro number. $\left(6.022 \times 10^{23} \mathrm{~mol}^{-1}\right)$

The experimental density of the prepared samples was calculated by Archimedes' principle with xylene media using the following relation.

$$
\begin{aligned}
& d_{E}=\frac{\text { Weight of the sample in air }}{\text { Weight of the sample in air-weight of the sample in xylene }} \times \text { Density of xylene } \\
& \text { The Percentage of Porosity } P \text { of the ferrite sample was then determined by employing } \\
& \qquad P=\frac{\mathrm{d}_{\mathrm{X}}-\mathrm{d}_{\mathrm{E}}}{\mathrm{d}_{\mathrm{X}}} \times 100
\end{aligned}
$$

Where $d_{x}$ is the $\mathrm{X}$-ray density $\& \mathrm{~d}_{\mathrm{E}}$ is the experimental density (bulk density).

The microstructure and surface morphology of prepared samples were examined by SEM (Hitachi-S520, Japan).

Magnetic hysteresis loops of all samples were recorded at room temperature using a VSM instrument. Magnetic parameters such as saturation magnetization $\left(M_{s}\right)$ remanent magnetization $\left(M_{r}\right)$ and coercivity $\left(H_{C}\right)$ were obtained from hysteresis loops and Anisotropic constant $(\mathrm{K})$ calculated using the following equation. [24].

$$
\text { Anisotropic constant } \mathrm{K}=\frac{\mathrm{M}_{\mathrm{S}} \mathrm{H}_{\mathrm{C}}}{0.96}
$$

Temperature-dependent DC electrical measurements were carried out using two probe method [25]. The resistivity ( $\rho$ ) and temperature (T) Kelvin relationship expressed as Arrhenius relation [26].

$$
\text { Resistivity } \rho=\rho_{\mathrm{o}} \mathrm{e}^{\Delta \mathrm{E} / \mathrm{k}_{\mathrm{B}} \mathrm{T}}
$$

The Arrhenius plots graph $\ln (\rho \mathrm{T})$ versus $10^{3} / \mathrm{T}$. It was observed that a change at a point on a plotted graph, it is known as Curie temperature and it indicates a change of magnetic ordering and dividing the curve into two regions, resultant to ferrimagentic region and paramagnetic region. From plots, graphs extract the slope and find the activation energy $(\Delta E)$ of each sample was calculated using the equation.

$$
\Delta E=(2.303) k_{B} 10^{3} \times \text { slope }(\mathrm{eV})
$$

Where, $\rho_{o}$ - Resistivity at room temperature,

$\mathrm{K}_{\mathrm{B}}$ - Boltzmann constant $\left(8.617 \times 10^{-5} \mathrm{eV} \mathrm{K}^{-1}\right)$ and $\Delta \mathrm{E}-$ Activation energy

Thermoelectric power was studied as a function of temperature and composition by the differential method [27-28]. Seebeck coefficient $(S)$ was calculated using the following relation.

$$
\mathrm{S}=\left(\frac{\Delta V}{\Delta T}\right)
$$

\section{Results and Discussion}

\subsection{XRD Analysis.}

XRD patterns of $\mathrm{NiSm}_{x} \mathrm{Fe}_{2-\mathrm{x}} \mathrm{O}_{4}(0.00 \leq x \leq 0.10)$ ferrites, heated at $500{ }^{\circ} \mathrm{C}$ for $4 \mathrm{~h}$ are shown in figure 1; it exhibits that crystalline phases were well defined and evaluation with PDF-4 reference data from the international center for diffraction data and indexed using ICDD card no (PDF\# 86-2267). The reflections from (220), (311), (222), (400), (511), and (440) planes confirmed a cubic unit cell, and (311) plane shows the spinel phase structure. So, these 
allowed planes confirmed the formation of single-phase having a cubic spinel structure [29]. The crystallite size was found in the range from $28.53 \mathrm{~nm}$ to $39.45 \mathrm{~nm}$.

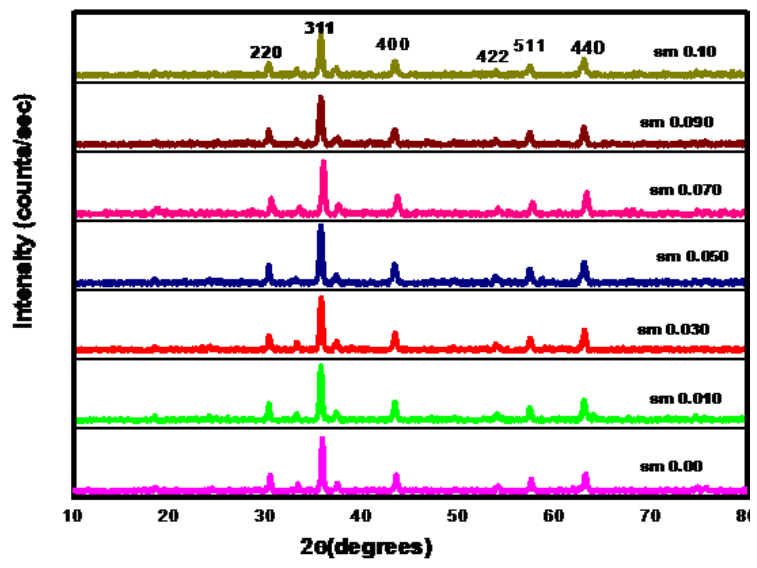

Figure 1. XRD pattern of Ni-Sm Nano ferrites.

The lattice parameter values of all the composition of Samarium doped Nickel ferrites have been calculated from the d- spacing and are reported in table 1. A graph is drawn between the lattice parameter with composition is shown in figure 2. It illustrates the variation of lattice constant with $\mathrm{Sm}^{+3}$ content in Ni ferrite. This is attributed to the replacement of smaller ionic radii $\mathrm{Fe}^{3+}$ by larger ionic radii $\mathrm{Sm}^{+3}$ ions.

Table 1.Structural parameters of Ni-Sm nano ferrites.

\begin{tabular}{l|l|l|l|l|l} 
Ferrite Composition & $\begin{array}{l}\text { Crystallite } \\
\text { size } \\
(\mathrm{nm})\end{array}$ & $\begin{array}{l}\text { Lattice } \\
\text { parameter } \\
a(\AA)\end{array}$ & $\begin{array}{l}\text { X-ray density } \\
d_{x}(\mathrm{gram} / \mathrm{cc})\end{array}$ & $\begin{array}{l}\text { Bulk density } \\
d_{E}(\mathrm{gram} / \mathrm{cc})\end{array}$ & $\begin{array}{l}\text { Porosity } \\
P(\%)\end{array}$ \\
\hline $\mathrm{NiFe}_{2} \mathrm{O}_{4}$ & 39.45 & 8.307 & 5.432 & 5.273 & 2.92 \\
\hline $\mathrm{Ni} \mathrm{Sm}_{0.010} \mathrm{Fe}_{1.99} \mathrm{O} 4$ & 33.37 & 8.338 & 5.393 & 5.347 & 0.85 \\
\hline $\mathrm{Ni} \mathrm{Sm} 0.030 \mathrm{Fe}_{1.97} \mathrm{O}_{4}$ & 30.72 & 8.061 & 6.162 & 5.338 & 13.37 \\
\hline $\mathrm{Ni} \mathrm{Sm} 0.050 \mathrm{Fe}_{1.95} \mathrm{O}_{4}$ & 30.74 & 8.329 & 5.679 & 5.360 & 5.61 \\
\hline $\mathrm{Ni} \mathrm{Sm} 0.070 \mathrm{Fe}_{1.93} \mathrm{O}_{4}$ & 31.65 & 8.281 & 5.638 & 5.381 & 4.55 \\
\hline $\mathrm{Ni} \mathrm{Sm} 0.090 \mathrm{Fe}_{1.91} \mathrm{O}^{4}$ & 28.53 & 8.458 & 5.332 & 5.320 & 0.22 \\
\hline $\mathrm{Ni} \mathrm{Sm} 0.10 \mathrm{Fe}_{1.9} \mathrm{O}_{4}$ & 29.53 & 8.334 & 5.596 & 5.389 & 3.69
\end{tabular}

Figure 3 shows the X-ray density $\left(d_{x}\right)$ with $\mathrm{Sm}^{+3}$ concentration. The X-ray density $\left(d_{x}\right)$ is depending on the lattice parameter and molecular weight of the sample. From table 1, we can observe that X-ray density, bulk density, and porosity variation with $\mathrm{Sm}^{+3}$ concentration. This is due to lattice parameter variation with Samarium concentration and also may due to the grater atomic weight of $\mathrm{Sm}$ is $150.36 \mathrm{gm} / \mathrm{mol}$, and the lesser atomic weight of $\mathrm{Fe}$ is $55.845 \mathrm{gm} / \mathrm{mol}$.

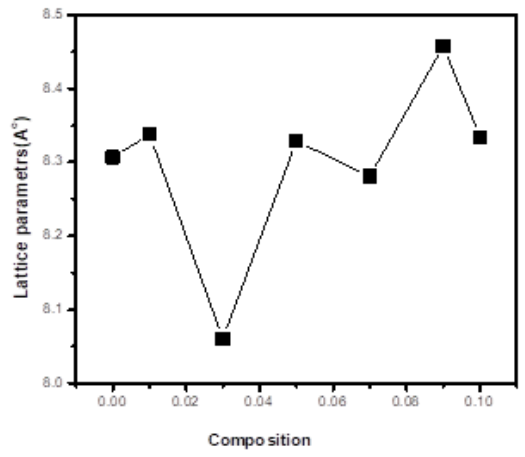

Figure 2. Variation of lattice constant with $\mathrm{Sm}^{+3}$ concentration. 


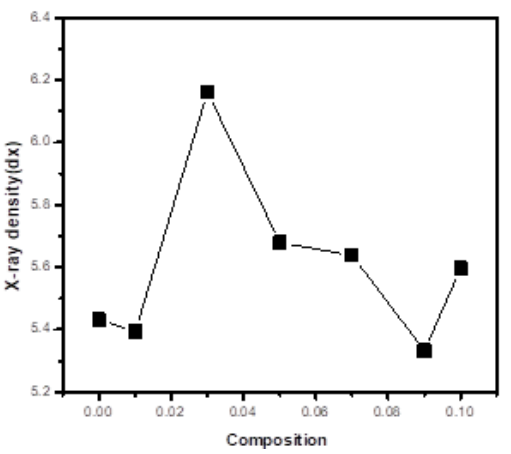

Figure 3. Variation of X-ray density $\left(\mathrm{d}_{\mathrm{x}}\right)$ with $\mathrm{Sm}^{+3}$ concentration.

\subsection{Morphology by SEM.}

Studied the microstructure and morphology of prepared samples using a scanning electron microscope (SEM). Where the secondary electron images were taken at different magnifications to study the synthesized samples surface morphology. The SEM images of NiSm ferrite are shown in figure 4. The images show that the particles have an almost homogeneous distribution, and some of the samples are agglomerated form. It evidenced by SEM images that the agglomeration of particles lies in the nano region. The particles were observed as uniform grain (in different SEM images) sizes.
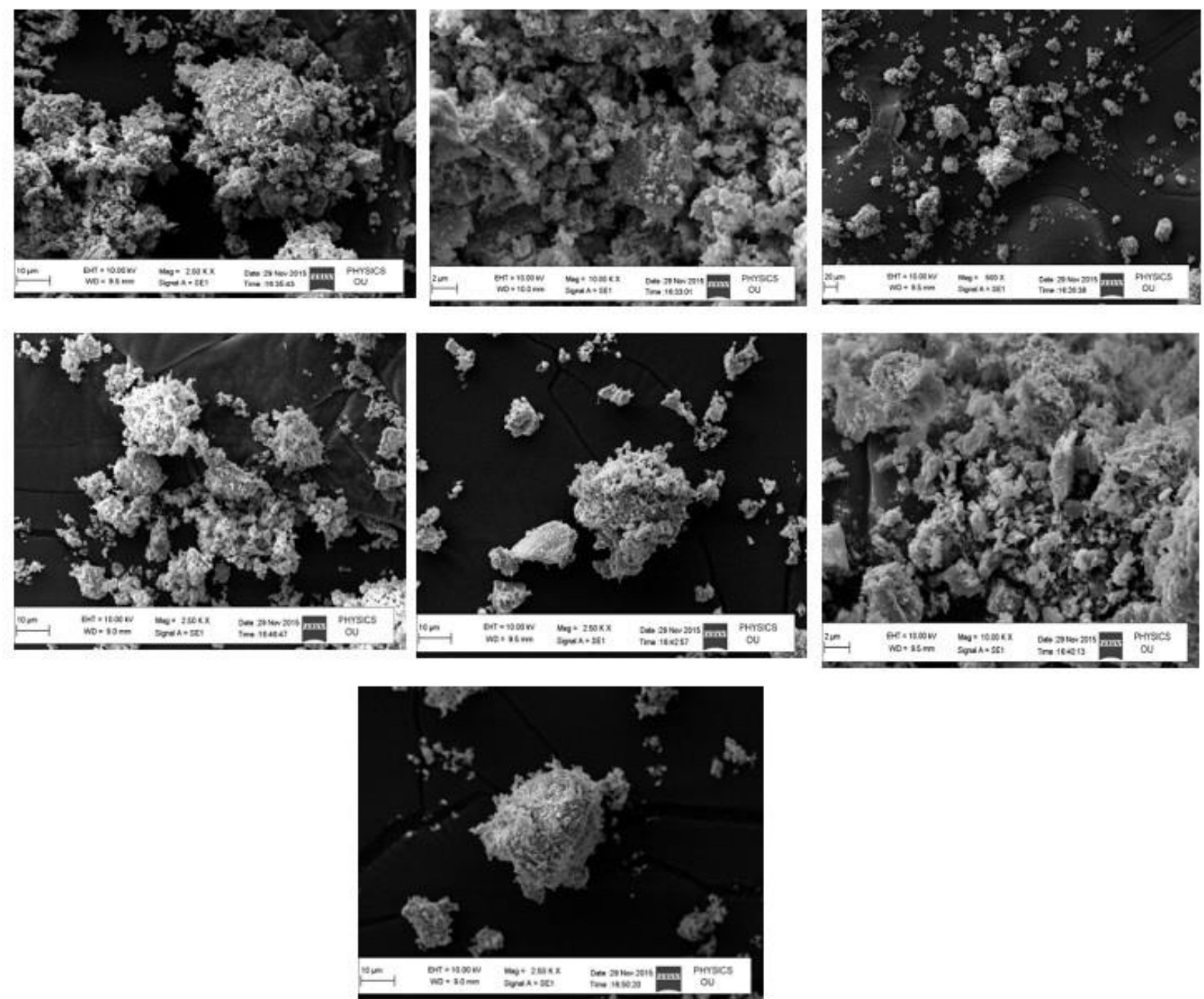

Figure 4. SEM micrographs of Ni-Sm nano ferrites. 


\subsection{Magnetic properties.}

Figure 5 shows magnetic hysteresis loops of prepared nano ferrite samples at room temperature with Vibrating Sample Magnetometer (VSM). With a maximum applied field of $20 \mathrm{kOe}$, the typical measurements are calculated from magnetic hysteresis loops of the samples with different Sm concentration. The hysteresis loops of nano ferrite samples shifts towards field axis with increases of the Samarium concentration in the Nickel nano ferrites.
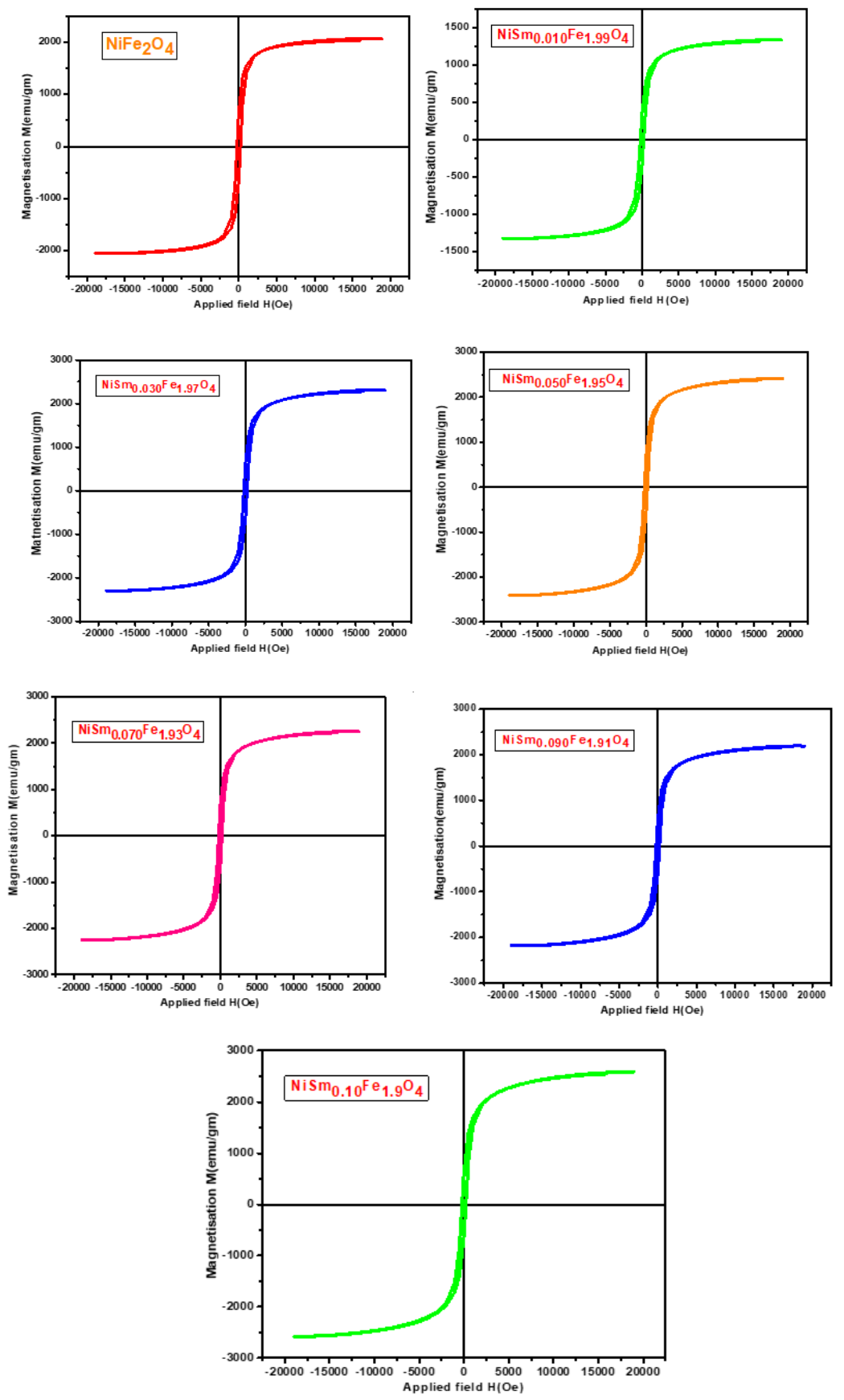

Figure 5. Magnetic hysteresis loops of $\mathrm{NiSm}_{X} \mathrm{Fe}_{2-\mathrm{X}} \mathrm{O}_{4}(0.00 \leq \mathrm{X} \leq 0.10)$ ferrites.

The resultant values of Saturation magnetization $(\mathrm{Ms})$, Remanent magnetization $\left(\mathrm{M}_{\mathrm{r}}\right)$, Coercive Field $H_{C}\left(\mathrm{O}_{\mathrm{e}}\right)$, and Anisotropic constant $(\mathrm{K})$ for the ferrites samples are shown in table 2. Increases of the Samarium content in Nickel-based ferrites the saturation magnetization will be increases. It attributed to the surface spin effect and cation distribution on A-site and B-site. The $\mathrm{Sm}^{3+}$ ion strongly occupies the Tetrahedral A-site [30-31]. $\mathrm{Ni}^{2+}$ ions occupy both 
Tetrahedral and Octahedral. The occupancy of $\mathrm{Sm}^{3+}$ ion at the tetrahedral site (A-site) successively replace $\mathrm{Fe}^{3+}$ ions from A-site and transfers an equal amount of $\mathrm{Fe}^{3+}$ ions to B-site. The strength of A-B interaction increases with the occupancy of $\mathrm{Sm}^{3+}$ ion in A-site with successive transfers of $\mathrm{Fe}^{3+}$ ions to $\mathrm{B}$-site. It is responsible for increases in saturation magnetization.

Table 2. Magnetic parameters of Ni-Sm nanoferrites.

\begin{tabular}{l|l|l|l|l} 
Ferrite Composition & $\begin{array}{l}\text { Saturation } \\
\text { Magnetization } \\
M_{S}(\text { emu/gr. }\end{array}$ & $\begin{array}{l}\text { Remanent } \\
\text { magnetization }(\mathrm{Mr})\end{array}$ & $\begin{array}{l}\text { Coercive } \\
\text { Field } \\
H_{C}\left(\mathrm{O}_{\mathrm{e}}\right)\end{array}$ & $\begin{array}{l}\text { Anisotropic } \\
\text { constant (K) }\end{array}$ \\
\hline $\mathrm{NiFe}_{2} \mathrm{O}_{4}$ & 2.060 & 0.66 & 228.26 & 490.53 \\
\hline $\mathrm{Ni} \mathrm{Sm} 0.010 \mathrm{Fe}_{1.99} \mathrm{O} 4$ & 2.202 & 0.53 & 226.99 & 520.65 \\
\hline $\mathrm{Ni} \mathrm{Sm} \mathrm{Sm}_{0.030} \mathrm{Fe}_{1.97} \mathrm{O}_{4}$ & 2.303 & 0.62 & 220.95 & 530.14 \\
\hline $\mathrm{Ni} \mathrm{Sm} \mathrm{S}_{0.050} \mathrm{Fe}_{1.95} \mathrm{O}_{4}$ & 2.411 & 0.66 & 215.13 & 540.29 \\
\hline $\mathrm{Ni} \mathrm{Sm} 0.070 \mathrm{Fe}_{1.93} \mathrm{O}_{4}$ & 2.254 & 0.64 & 219.05 & 514.31 \\
\hline $\mathrm{Ni} \mathrm{Sm}_{0.090} \mathrm{Fe}_{1.91} \mathrm{O}^{4}$ & 2.188 & 0.55 & 207.56 & 473.06 \\
\hline $\mathrm{Ni} \mathrm{Sm} 0.10 \mathrm{Fe}_{1.9} \mathrm{O}_{4}$ & 2.583 & 0.60 & 206.69 & 556.12
\end{tabular}

\subsection{Electrical properties.}

Figure 6 illustrates the variation of the DC electrical conductivity with temperature for $\mathrm{NiSm}_{x} \mathrm{Fe}_{2} \mathrm{xO}_{4}(0.00 \leq X \leq 0.10)$ nano ferrite samples ferrites. It is clear that which the conductivity decreases with an increase in temperature for each sample, which is a normal behavior of semiconductors [32]. It can be explained well with Verway's hopping mechanism [33]. When $\mathrm{Sm}^{3+}$ ion-doped for $\mathrm{Fe}^{3+}, \mathrm{Sm}^{3+}$ ions partially occupy on the A sites, then some $\mathrm{Fe}$ ions are shifted from $\mathrm{A}$ to $\mathrm{B}$ sites. Hence $\mathrm{Ni}^{2+}$ ions decrease on $\mathrm{B}$ sites. Consequently, the number of $\mathrm{Fe}^{2+} \Leftrightarrow \mathrm{Fe}^{3+}$ ions increase on the B sites. As a result, the electrical resistivity decreases, and conductivity increases with $\mathrm{Sm}^{3+}$ substitution $(x)$. Similar behavior was observed and reported by other researchers [34-35]. $\mathrm{Fe}^{2+}$ was interpreted based on the cation distribution of Ni-Sm nano-ferrites.

From figure 6, It was observed that a change at a point, it indicates a change of magnetic ordering and dividing the curve into two regions, resultant to the ferrimagnetic region and paramagnetic region. According to the magnetic semiconductor theory, the ferrimagnetic region is an ordered one, while the paramagnetic region is disordered one [36]. Therefore, for the conduction in the paramagnetic region, more energy is required compared with the ferrimagnetic region. Hence, the activation energy in the paramagnetic region $\left(E_{P}\right)$ is found greater than in the ferrimagnetic region $\left(E_{F}\right)$. Similar results were reported by others in $\mathrm{Zn}-\mathrm{Ni}$ ferrites [37]. The activation energy values in the paramagnetic region and ferromagnetic region and Curie temperature value are reported in table 3.

Table 3. Electrical properties $\mathrm{NiSm}_{\mathrm{X}} \mathrm{Fe}_{2-\mathrm{X}} \mathrm{O}_{4}$ nano ferrite samples $(0.0 \leq \mathrm{x} \leq 1.0)$.

\begin{tabular}{c|c|c|c|c} 
Ferrite Composition & $\begin{array}{c}\text { Curie Temperature } \\
\mathrm{T}_{\mathrm{c}}(\mathrm{K})\end{array}$ & $\begin{array}{c}\text { Para Region }\left(E_{P}\right) \\
\mathrm{eV}\end{array}$ & $\begin{array}{c}\text { Ferri Region }\left(E_{F}\right) \\
\mathrm{eV}\end{array}$ & $\begin{array}{c}\text { Transition temperature } \\
\mathrm{T}_{\mathrm{s}}(\mathrm{K})\end{array}$ \\
\hline $\mathrm{NiFe}_{2} \mathrm{O}_{4}$ & 610 & 0.975 & 0.912 & 765 \\
\hline $\mathrm{Ni} \mathrm{Sm} \mathrm{Se}_{0.010} \mathrm{Fe}_{1.99} \mathrm{O} 4$ & 594 & 0.941 & 0.883 & 752 \\
\hline $\mathrm{Ni} \mathrm{Sm} 0.030 \mathrm{Fe}_{1.97} \mathrm{O}_{4}$ & 579 & 0.829 & 0.751 & 737 \\
\hline $\mathrm{Ni} \mathrm{Sm} \mathrm{Sm}_{0.050} \mathrm{Fe}_{1.95} \mathrm{O}_{4}$ & 566 & 0.775 & 0.711 & 722 \\
\hline $\mathrm{Ni} \mathrm{Sm}_{0.070} \mathrm{Fe}_{1.93} \mathrm{O}_{4}$ & 551 & 0.691 & 0.642 & 692 \\
\hline $\mathrm{Ni} \mathrm{Sm} 0.090 \mathrm{Fe}_{1.91} \mathrm{O}^{4}$ & 538 & 0.624 & 0.581 & 675
\end{tabular}




\subsection{Thermoelectric power studies.}

The Variation of Seebeck coefficient (S) with the temperature of the prepared Ni-Sm nano ferrites was shown in figure 7. It was observed that the Seebeck coefficient increases with an increase in the temperature up to a particular temperature are called Transition temperature and beyond the Transition temperature Seebeck coefficient decreases.

At low temperature, a positive value of the Seebeck coefficient shows the p-type semiconducting nature of the prepared ferrite samples. By increasing the temperature and increasing the Sm composition, the Seebeck coefficient increases. Beyond the transition temperature Seebeck coefficient start decreases, and it shows a negative value of the Seebeck coefficient. Therefore at a higher temperature, the samples have behaved as n-type semiconductor nature [38]. The probable conduction mechanisms in the spinel nano ferrite system under investigation are $\mathrm{Fe}^{2+} \leftrightarrow \mathrm{Fe}^{3+}+\mathrm{e}^{-}$(n-type or electron exchange mechanism) [39].

If the hole exchange mechanism dominates over the electron exchange mechanism, the ferrite composition might conduct as a p-type semiconductor or vice versa. On increasing the temperature, the n-type of conduction mechanism becomes more probable, which generates electrons and the material behaves as an n-type semiconductor at a higher temperature. Hence the material was behaving as a p-type semiconductor at the low-temperature region and changes to n-type at the high-temperature region. A similar tendency was reported by other researchers [40-41]. The transition temperature Ts (K) are reported in table 3, and these values well agree with Curie temperature $\mathrm{Tc}(\mathrm{K})$, which are reported from DC electrical properties.
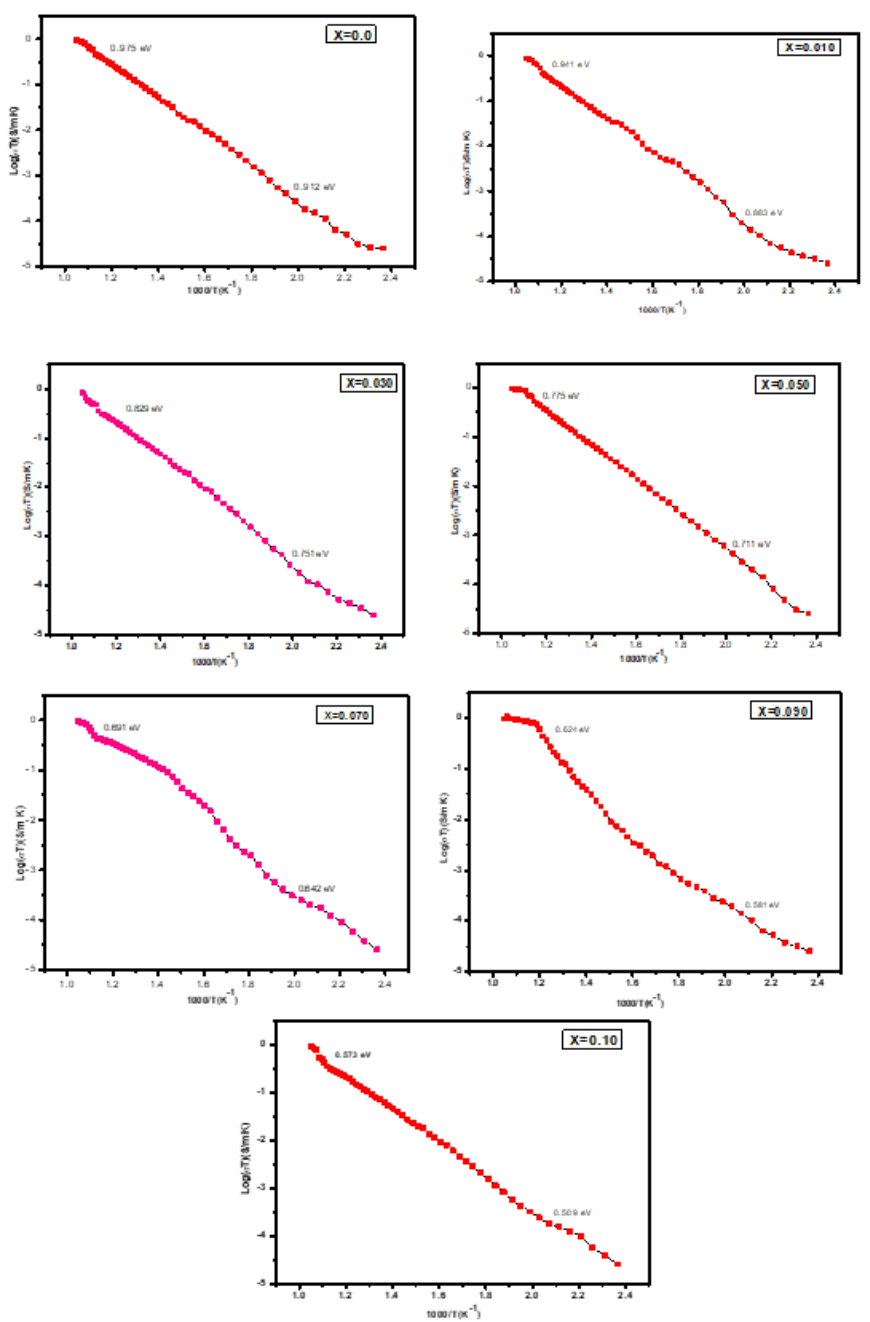

Figure 6. Temperature-dependent dc conductivity graphs of $\mathrm{NiSm}_{\mathrm{X}} \mathrm{Fe}_{2-\mathrm{X}} \mathrm{O}_{4}$ nano ferrite samples $(0.00 \leq \mathrm{X} \leq 0.10)$ 

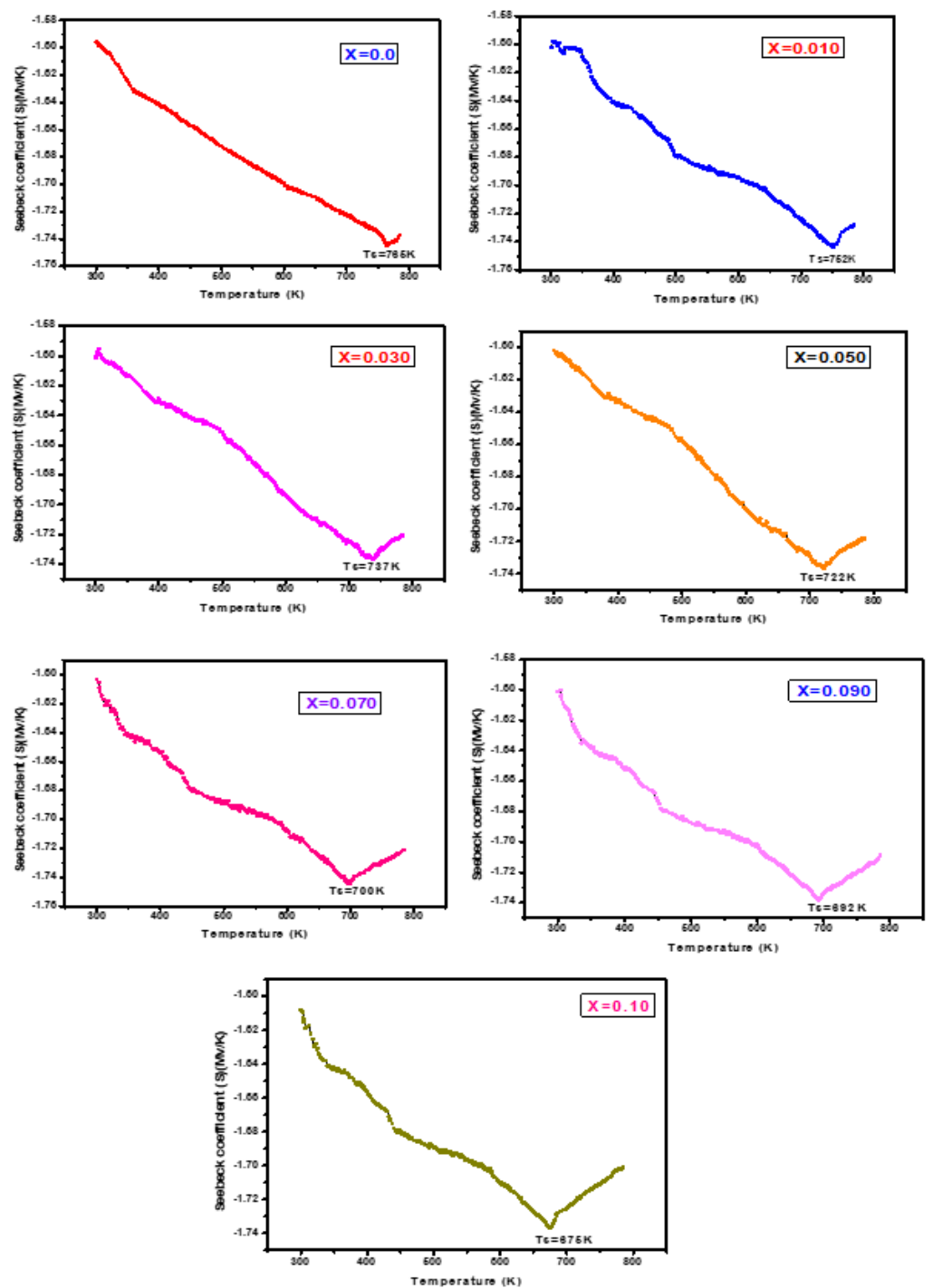

Figure 7. Seebeckcoefficient variation with temperature $(\mathrm{K})$ of $\mathrm{NiSm}_{\mathrm{X}} \mathrm{Fe}_{2-\mathrm{X}} \mathrm{O}_{4}(0.00 \leq \mathrm{X} \leq 0.10)$

\section{Conclusions}

The citrate Gel Auto Combustion technique is a very simple and economical method, where no specific heating or cooling rate is required. X-ray diffraction pattern confirms the formation of a single-phase cubic spinel structure, and crystalline size is in the range of 28 to $39 \mathrm{~nm}$. SEM micrographs are revealing largely agglomerated. Saturation magnetization increases with Sm consternation increases. The variation of dc conductivity with temperature shows semiconducting behavior. Temperature-dependent Seebeck coefficient explains at low temperature, a positive value of Seebeck coefficient shows p-type semiconducting nature, and at a higher temperature, the samples have behaved as n-type semiconductor nature.

\section{Funding}

This research received no external funding.

\section{Acknowledgments}

The author Gopal Boda conveys his sincere thanks to Prof. A.PanasaReddy, for his keen encouragement and guidance and RGNF-NFST, New Delhi for awarding national fellowship to do Ph.d. The authors are also-grateful to the Head Department of Chemistry, University 
College of Science Osmania University Hyderabad. One of the authors, D.R.is grateful to O.U.UPE-FAR and O.U. DST PURSE, New Delhi, for their financial assistance.

\title{
Conflicts of Interest
}

\author{
The authors declare no conflict of interest.
}

\section{References}

1. Shirsath, S.E.; Wang, D.; Jadhav, S.S.; Mane, M.L.; Li, S. inFerrites Obtained by Sol-Gel Method, Handbook of Sol-Gel Science and Technology. Klein, L.; Aparicio, M.; Jitianu, A. Springer, Cham, 2018 ;pp. 695-735.

2. Cao, M.S.; Wang, X.X.; Zhang, M.; Shu, J.C.; Cao, W.Q.; Yang, H.J.; Fang, X.Y.; Yuan, J. Electromagnetic Response and Energy Conversion for Functions and Devices in Low-Dimensional Materials. Advanced Functional Materials 2019, 29, https://doi.org/10.1002/adfm.201807398.

3. Li, Y.; Cao, W.-q.; Yuan, J.; Wang, D.-w.; Cao, M.-s. Nd doping of bismuth ferrite to tune electromagnetic properties and increase microwave absorption by magnetic-dielectric synergy. Journal of Materials Chemistry C 2015, 3, 9276-9282, https://doi.org/10.1039/C5TC01684C.

4. Ramos, A.V.; Santos, T.S.; Miao, G.X.; Guittet, M.J.; Moussy, J.B.; Moodera, J.S.Influence of oxidation on the spin-filtering properties of $\mathrm{CoFe}_{2} \mathrm{O}_{4}$ and the resultant spin polarization.Phys. Rev. B 2008, 78(R), https://doi.org/10.1103/PhysRevB.78.180402.

5. Shirsath, S.E.; Liu, X.; Assadi, M.H.N.; Younis, A.; Yasukawa, Y.; Karan, S.K.; Zhang, J.; Kim, J.; Wang, D.; Morisako, A.; Yamauchi, Y.; Li, S. Au quantum dots engineered room temperature crystallization and magnetic anisotropy in $\mathrm{CoFe} 2 \mathrm{O} 4$ thin films. Nanoscale Horizons 2019, 4, 434-444, https://doi.org/10.1039/C8NH00278A.

6. Quickel, T.E.; Le, V.H.; Brezesinski, T.; Tolbert, S.H. On the Correlation between Nanoscale Structure and Magnetic Properties in Ordered Mesoporous Cobalt Ferrite (CoFe2O4) Thin Films. Nano Letters 2010, 10, 2982-2988, http://doi.org/10.1021/nl1014266.

7. Gawas, S.G.; Meena, S.S.; Yusuf, S.M.; Verenkar, V.M.S. Anisotropy and domain state dependent enhancement of single domain ferrimagnetism in cobalt substituted $\mathrm{Ni}-\mathrm{Zn}$ ferrites. New Journal of Chemistry 2016, 40, 9275-9284, https://doi.org/10.1039/C6NJ02121B.

8. Emadi, H.; Mobarak,H. Synthesis and characterization of copper ferrite nanoparticles and its application as MRI contrast agent. Letters in Applied NanoBioScience 2019, 8,541-544, https://doi.org/10.33263/LIANBS81.541544.

9. Obaidat, I.M.; Issa, B.; Haik, Y. Magnetic Properties of Magnetic Nanoparticles for Efficient Hyperthermia. Nanomaterials 2015, 5, 63-89, https://doi.org/10.3390/nano5010063.

10. Abdel Maksoud, M.I.A.; El-Sayyad, G.S.; Ashour, A.H.; El-Batal, A.I.; Abd-Elmonem, M.S.; Hendawy, H.A.M.; Abdel-Khalek, E.K.; Labib, S.; Abdeltwab, E.; El-Okr, M.M. Synthesis and characterization of metals-substituted cobalt ferrite [ $\mathrm{Mx} \mathrm{Co}(1-\mathrm{x}) \mathrm{Fe} 2 \mathrm{O} 4 ;(\mathrm{M}=\mathrm{Zn}, \mathrm{Cu}$ and $\mathrm{Mn} ; \mathrm{x}=0$ and 0.5)] nanoparticles as antimicrobial agents and sensors for Anagrelide determination in biological samples. Materials Science and Engineering: C 2018, 92, 644-656, https://doi.org/10.1016/j.msec.2018.07.007.

11. Gangwar, A.; Alla, S.K.; Srivastava, M.; Meena, S.S.; Prasadrao, E.V.; Mandal, R.K.; Yusuf, S.M.; Prasad, N.K. Structural and magnetic characterization of $\mathrm{Zr}$-substituted magnetite (ZrxFe3-xO4, $0 \leq \mathrm{x} \leq 1)$. Journal of Magnetism and Magnetic Materials 2016, 401, 559-566, http://dx.doi.org/10.1016/j.jmmm.2015.10.087.

12. Banerjee, A.M.; Pai, M.R.; Meena, S.S.; Tripathi, A.K.; Bharadwaj, S.R. Catalytic activities of cobalt, nickel and copper ferrospinels for sulfuric acid decomposition: The high temperature step in the sulfur based thermochemical water splitting cycles. International Journal of Hydrogen Energy 2011, 36, 4768-4780, http://dx.doi.org/10.1016/j.ijhydene.2011.01.073.

13. Ghosh, R.; Pradhan, L.; Devi, Y.P.; Meena, S.S.; Tewari, R.; Kumar, A.; Sharma, S.; Gajbhiye, N.S.; Vatsa, R.K.; Pandey, B.N.; Ningthoujam, R.S. Induction heating studies of Fe3O4 magnetic nanoparticles capped with oleic acid and polyethylene glycol for hyperthermia. Journal of Materials Chemistry 2011, 21, 1338813398, https://doi.org/10.1039/C1JM10092K.

14. Srivastava, M.; Alla, S.K.; Meena, S.S.; Gupta, N.; Mandal, R.K.; Prasad, N.K. ZnxFe3-xO4 $(0.01 \leq x \leq$ 0.8) nanoparticles for controlled magnetic hyperthermia application. New Journal of Chemistry 2018, 42, 7144-7153, https://doi.org/10.1039/C8NJ00547H.

15. Zhang, M.; Yang, H.J.; Li, Y.; Cao, W.Q.; Fang, X.Y.; Yuan, J.; Cao, M.S. Cobalt doping of bismuth ferrite for matched dielectric and magnetic loss.Appl. Phys. Lett. 2019, 115, https://doi.org/10.1063/1.5134741.

16. Akhtar, M.N.; Khan, M.A. Effect of rare earth doping on the structural and magnetic features of nanocrystalline spinel ferrites prepared via sol gel route. Journal of Magnetism and Magnetic Materials 2018, 460, 268-277,https://doi.org/10.1016/j.jmmm.2018.03.069.

17. Junaid, M.; Khan, M.A.; Iqbal, F.; Murtaza, G.; Akhtar, M.N.; Ahmad, M.; Shakir, I.; Warsi, M.F. Structural, spectral, dielectric and magnetic properties of $\mathrm{Tb}-\mathrm{Dy}$ doped Li-Ni nano-ferrites synthesized via micro- 
emulsion route. Journal of Magnetism and Magnetic Materials 2016, 419, 338-344, https://doi.org/10.1016/j.jmmm.2016.06.043.

18. Qindeel, R.; Alonizan, N.H. Structural, dielectric and magnetic properties of cobalt based spinel ferrites. Current Applied Physics 2018, 18, 519-525,https://doi.org/10.1016/j.cap.2018.03.004.

19. Ahmad, S.I.; Rauf, A.; Mohammed, T.; Bahafi, A.; Ravi Kumar, D.; Suresh, M.B. Dielectric, impedance, AC conductivity and low-temperature magnetic studies of Ce and Sm co-substituted nanocrystalline cobalt ferrite. Journal of Magnetism and Magnetic Materials, 2019, 492, https://doi.org/10.1016/j.jmmm.2019.165666.

20. Karimunnesa, S.; Ullah, A.K.M.A.; Hasan, M.R.; Shanta, F.S.; Islam, R.; Khan, M.N.I. Effect of holmium substitution on the structural, magnetic and transport properties of CoFe2-xHoxO4 ferrites. Journal of Magnetism and Magnetic Materials 2018, 457, 57-63, https://doi.org/10.1016/j.jmmm.2018.02.077.

21. von Ardenne, M. Das Elektronen-Rastermikroskop. Zeitschrift für Physik 1938, 109, 553-572, https://doi.org/10.1007/BF01341584.

22. Ladgaonkar, B.P.; Bakare, P.P.; Sainkar, S.R.; Vaingankar, A.S. Influence of Nd3+ substitution on permeability spectrum of $\mathrm{Zn}-\mathrm{Mg}$ ferrite. Materials Chemistry and Physics 2001, 69, 19-24, https://doi.org/10.1016/S0254-0584(00)00294-7.

23. Kambale, R.C.; Shaikh, P.A.; Kamble, S.S.; Kolekar, Y.D. Effect of cobalt substitution on structural, magnetic and electric properties of nickel ferrite. Journal of Alloys and Compounds 2009, 478, 599-603, https://doi.org/10.1016/j.jallcom.2008.11.101.

24. Kambale, R.C.; Song, K.M.; Koo, Y.S.; Hur, N. Low temperature synthesis of nanocrystalline Dy3+ doped cobalt ferrite: Structural and magnetic properties. Journal of Applied Physics 2011, 110, https://doi.org/10.1063/1.3632987.

25. Iqbal, M.J.; Ashiq, M.N.; Hernandez-Gomez, P.; Munoz, J.M. Synthesis, physical, magnetic and electrical properties of Al-Ga substituted co-precipitated nanocrystalline strontium hexaferrite. Journal of Magnetism and Magnetic Materials 2008, 320, 881-886, https://doi.org/10.1016/j.jmmm.2007.09.005.

26. Sridhar, R.; Ravinder, D.; Kumar, K.V. Dielectric properties of copper substituted nickel nanoferrites.Journal of Engineering Research and Applications 2015, 3, 2021-2024.

27. Hoque, S.M.; Choudhury, M.A.; Islam, M.F. Characterization of Ni-Cu mixed spinel ferrite. Journal of Magnetism and Magnetic Materials 2002, 251, 292-303, https://doi.org/10.1016/S0304-8853(02)00700-X.

28. Kolekar, C.B.; Kamble, P.N.; Kulkarni, S.G.; Vaingankar, A.S. Effect of Gd3+ substitution on dielectric behaviour of copper-cadmium ferrites. Journal of Materials Science 1995, 30, 5784-5788, https://doi.org/10.1007/BF00356721.

29. Khan, M.H.R.; Hossain, A.K.M.A. Reentrant spin glass behavior and large initial permeability of Co0.5-xMnxZn0.5Fe2O4. Journal of Magnetism and Magnetic Materials 2012, 324, 550-558, https://doi.org/10.1016/j.jmmm.2011.08.039.

30. Ribeiro, V.A.D.S.; Rubinger, R.M.; Oliveira, A.F.; Mendonça, C.S.P.; Silva, M.R.d. Magnetic properties and potential barrier between crystallites model of MgGa2-xFexO4 ceramics. J Cerâmica 2016, 62, 365369, https://doi.org/10.1590/0366-69132016623642006.

31. Hemeda, O.M.; Barakat, M.M. Effect of hopping rate and jump length of hopping electrons on the conductivity and dielectric properties of $\mathrm{Co}-\mathrm{Cd}$ ferrite. Journal of Magnetism and Magnetic Materials 2001, 223, 127-132, https://doi.org/10.1016/S0304-8853(00)00521-7.

32. Reddy, V.D.; Malik, M.A.; Reddy, P.V. Electrical transport properties of manganese-magnesium mixed ferrites. Materials Science and Engineering: B 1991, 8, 295-301, https://doi.org/10.1016/09215107(91)90050-6.

33. Van Uitert, L.G. High-Resistivity Nickel Ferrites - the Effect of Minor Additions of Manganese or Cobalt. The Journal of Chemical Physics 1956, 24, 306-310, https://doi.org/10.1063/1.1742468.

34. Baijal, J.S.; Phanjoubam, S.; Kothari, D.; Prakash, C.; Kishan, P. Hyperfine interactions and magnetic studies of Li-Mg ferrites. Solid State Communications 1992, 83, 679-682, https://doi.org/10.1016/00381098(92)90144-X.

35. Kumar, K.V.; Sridhar, R.; Ravinder, D.; Krishna, K.R. Structural properties and electrical conductivity of copper substituted nickel nano ferrites.International Journal of Applied Physics and Mathematics 2014, 4,113-117, https://doi.org/10.7763/IJAPM.2014.V4.265.

36. Sridhar, R.; Ravinder, D.; Kumar, K.V. Synthesis and Characterization of Copper Substituted Nickel NanoFerrites by Citrate-Gel Technique. Advances in Materials Physics and Chemistry 2012, 2, 192-199, https://doi.org/10.4236/ampc.2012.23029.

37. El-Shabasy, M. DC electrical properties of ZnNi ferrites. Journal of Magnetism and Magnetic Materials 1997, 172, 188-192, https://doi.org/10.1016/S0304-8853(97)00014-0.

38. Walz, F. The Verwey transition - a topical review. Journal of Physics: Condensed Matter 2002, 14, R285R340, https://doi.org/10.1088/0953-8984/14/12/203.

39. Verwey, E.J.; Haayman, P.W.; Romeijn, F.C. Physical Properties and Cation Arrangement of Oxides with Spinel Structures II. Electronic Conductivity. The Journal of Chemical Physics 1947, 15, 181-187, https://doi.org/10.1063/1.1746466. 
40. Rlinger, M.I.; Samokhvalov, A.A. Electron conduction in magnetite and ferrites. physica status solidi (b) 1977, 79, 9-48, https://doi.org/10.1002/pssb.2220790102.

41. ridhar, R.; Ravinder, D.; Vijaya Kumar, K. Temperature-dependence thermoelectric power studies of mixed $\mathrm{Ni}-\mathrm{Cu}$ nano ferrites. Journal of Alloys and Compounds 2015, 645, 436-442, https://doi.org/10.1016/j.jallcom.2015.05.041. 